\title{
An Anatomy of Price Dynamics in Illiquid Markets: Analysis and Evidence from Local Housing Markets
}

Dennis R. Capozza, ${ }^{*}$ Patric H. Hendershott, ${ }^{* *}$ and Charlotte Mack***

This research analyzes the dynamic properties of the difference equation that arises when markets exhibit serial correlation and mean reversion. We identify the correlation and reversion parameters for which prices will overshoot equilibrium ("cycles") and/or diverge permanently from equilibrium. We then estimate the serial correlation and mean reversion coefficients from a large panel data set of 62 metro areas from 1979 to 1995 conditional on a set of economic variables that proxy for information costs, supply costs and expectations. Serial correlation is higher in metro areas with higher real incomes, population growth and real construction costs. Mean reversion is greater in large metro areas and faster growing cities with lower construction costs. The average fitted values for mean reversion and serial correlation lie in the convergent oscillatory region, but specific observations fall in both the damped and oscillatory regions and in both the convergent and divergent regions. Thus, the dynamic properties of housing markets are specific to the given time and location being considered.

Numerous studies of a variety of asset markets have documented the existence of short-horizon serial correlation and long-horizon mean reversion in asset prices. Among asset markets, the most heavily researched is the equity market. For example, Fama and French (1988) and Poterba and Summers (1988), using different methodologies, find significant evidence of mean reversion at long horizons. Fama and French conclude "predictable variation is estimated to be about $40 \%$ of 3-5 year return variances for portfolios of small firms" (p. 246). ${ }^{1}$ Time varying equilibrium expected returns and investor overreaction have

*University of Michigan Business School, Ann Arbor, MI 48109 or Capozza@ umich. edu.

**University of Aberdeen Business School, Aberdeen, Scotland, UK or phh3939@ uslink.net.

***University of Michigan, Ann Arbor, MI 48109 or CYM@ umich.edu.

${ }^{1}$ A recent study that models "fundamental" value using dividends and earnings is Chiang, Davidson and Okunev (1997). 
been proposed as possible explanations. ${ }^{2}$ Momentum strategies, which exploit serial correlation in asset prices, have been shown to be more profitable when information costs are high (Hong, Lim and Stein 2000).

The focus of our research is the more illiquid U.S. single-family housing market. Earlier studies have documented both serial correlation and mean reversion (Case and Shiller 1989, Abraham and Hendershott 1993, 1996, Capozza and Seguin 1996, Capozza, Mack and Mayer 1997, Malpezzi 1999, Meen 2002). One intriguing finding in these studies is that the extent of correlation or reversion varies with location. For example, Abraham and Hendershott (1996) document a significant difference in time-series properties between coastal and inland cities.

Since studies that use a wide variety of methodologies and cover many time periods, countries and asset types all find evidence of serial correlation and mean reversion, this characteristic may be a pervasive and ubiquitous feature of asset markets. Some logical questions to ask are: What variables might affect the time-series properties; why do regions react differently to economic shocks, ${ }^{3}$ and does the same region react differently over time? Our empirical tests focus on the interaction among the serial correlation and mean reversion coefficients and economic forces.

In this research we first provide more definition to the dynamics by translating the standard empirical formulation for estimating serial correlation and mean reversion into the corresponding second-order difference equation. We then analyze the properties of the difference equation to derive the required values that produce the four major dynamic structures: damped versus cyclical and convergent versus divergent or explosive. By first defining the mathematical structure implied by the empirical estimates, we are able to give rigorous definition to terms like "overshooting" and "bubble."

In the context of the dynamics implied by the difference equation arising from this simple model, overshooting occurs when the correlation and reversion coefficient pairs assume values in the "oscillatory" region where the roots of the "characteristic" or "complementary" function of the difference equation

\footnotetext{
2 There is a long literature in international trade that explains exchange rate movements as reversion to purchasing power parity (fundamental value). A recent example that uses panel data is Frankel and Rose (1996), which finds "strong evidence of mean reversion that is similar to that from long time-series" (p. 209).
}

3 A recent contribution by Lamont and Stein (1999, p. 498) finds that "where homeowners are more leveraged ... house prices react more sensitively to city-specific shocks." 
are complex. ${ }^{4}$ Mathematically, a coefficient pair that lies in the divergent or explosive region is one way to define a "bubble." This divergent behavior arises when the serial correlation exceeds one.

We then estimate the correlation and reversion parameters using a large panel data set for 62 U.S. metropolitan areas from 1979 to 1995 . The data set includes economic, demographic and political variables for each of the metro areas. We explore several hypotheses based on information or transaction costs, supply costs and expectations. Housing is highly heterogeneous so that participants have difficulty assessing the instantaneous "true" price for any given property. In general (Quan and Quigley 1991), an optimal "appraisal” weights current and past transactions prices of similar properties. As a result transaction frequency can affect the rate of information dissemination in a housing market. Transaction frequency also affects reservation prices in search models of the housing market (Wheaton 1990). Whenever economic or demographic variables affect transaction frequency, some metro areas may react either faster or with more amplitude to a given economic shock than other areas.

Further, any given positive economic shock will be easier for an area to absorb if the housing stock can be increased quickly and at low cost. Therefore we hypothesize that variables proxying for the cost and difficulty of adding to the supply of housing should affect the time-series properties of housing prices. To preview the conclusions, we find evidence that both information dissemination and supply factors influence the dynamics of housing prices. We also find that the dynamics can vary over time and over locations. Most often the coefficients lie in the convergent regions; however, there are time periods and locations where the estimates lie in the divergent or explosive region.

Our contributions are first to provide a more rigorous structure for discussions of house price dynamics based on serial correlation and mean reversion by analyzing the implied difference equation. Second, we provide additional evidence on serial correlation and mean reversion in housing markets using a much larger panel data set than in previous research. Our results are consistent with earlier estimates but lie at the upper end of their range. Third, and most importantly, we model and estimate equations relating the extent of serial correlation and mean reversion to possible determinants such as information dissemination, supply constraints and backward-looking expectation formation.

In the next section we solve the difference equation and characterize its dynamic properties. The third section describes the panel data set we use for our estimates,

\footnotetext{
${ }_{4}$ There are many fine references for difference equations in mathematical economics texts. Lucid expositions appear in Chiang (1984) and Sysdaeter and Hammond (1995).
} 
and the fourth section discusses the empirical results. The fitted values for the coefficients indicate the wide variation in possible dynamics. The final section summarizes and concludes with suggestions for future research and implications for policymakers.

\section{Dynamics in the Standard Model}

Underlying the concept of mean reversion is the basic notion that, in the long run, markets tend towards equilibrium. Therefore, we assume that in each time period, $t$, and in each metro area there is a long-run equilibrium value for the unit price of housing space that is determined by economic conditions:

$P_{t}^{*}=p\left(\boldsymbol{X}_{t}\right)$,

where $P^{*}$ is the $\log$ of real equilibrium value per quality adjusted square foot of space in the metro area and $\boldsymbol{X}_{t}$ is a vector of exogenous explanatory variables. In general, a relationship like Equation (1) can be viewed as the reduced form arising from a supply-and-demand relationship. In an urban context, (1) can arise from any open city model of urban equilibrium. For the empirical results that follow, we base our specification of Equation (1) on the urban asset-pricing model of Capozza and Helsley (1989). ${ }^{5}$ In the vector, $\boldsymbol{X}$, we include the size of a metro area (population level and real income), the real construction cost of converting land from agricultural use to new residential structures, expected growth and the user cost of owner-occupied housing as well as proxies for regulatory conditions. ${ }^{6}$

Value changes in the standard model are governed by reversion to this equilibrium value and by serial correlation according to ${ }^{7}$

$\Delta P_{t}=\alpha \Delta P_{t-1}+\beta\left(P_{t-1}^{*}-P_{t-1}\right)+\gamma \Delta P_{t}^{*}$,

where $P_{t}$ is the log of real house values at time $t$ and $\Delta$ is the difference operator. The first term on the right in (2) is the serial correlation term where $\alpha$ is the serial

\footnotetext{
${ }^{5}$ Other research on dynamics that has based the empirical estimates on this model include Abraham and Hendershott (1996) and Capozza, Green and Hendershott (1996).

${ }^{6}$ The choice of exogenous variables, $\boldsymbol{X}$, will be important for the estimates that follow. Empirical models that incorporate mean reversion are known as error correction models (ECM). When estimating an ECM, the econometric properties hinge on the existence of a "cointegrating" relationship for the variables in Equation (1). A cointegrating relationship will arise when an equilibrium relationship exists among the variables.

${ }^{7}$ In an urban context, variations on (2) appear in the earlier work of Abraham and Hendershott (1996), Capozza, Mack and Mayer (1997), Lamont and Stein (1999), Malpezzi (1999) and Meen (2002), among others.
} 
correlation coefficient. The second error correction term causes reversion to the equilibrium value with $\beta(0<\beta<1)$ being the rate of reversion or adjustment to equilibrium. The third term captures the contemporaneous adjustment to fundamentals. Partial adjustment implies that $0 \leq \gamma \leq 1$.

Equation (2) can be rewritten in difference equation form by substituting $P_{t}-$ $P_{t-1}$ for $\Delta P_{t}$.

$P_{t}-(1+\alpha-\beta) P_{t-1}+\alpha P_{t-2}=\gamma P_{t}^{*}+(\beta-\gamma) P_{t-1}^{*}$.

In general, $P_{t}^{*}$ will be stochastic; however, much can be gleaned about the dynamic properties of (2) from the illustrative case where $P_{t}^{*}=P^{*}$, a constant, and $P_{0} \neq P^{*}$. Equation (3), then, is a second-order difference equation of the form

$P_{t+2}+a_{1} P_{t+1}+a_{2} P_{t}=K$,

where $a_{1}, a_{2}$, and $K$ are all constants.

The dynamic behavior of (3) is studied by applying the "z-transform," $B^{n}=P_{n}$, and then analyzing the resulting "characteristic" or complementary functions of the difference equation in (3) given by the quadratic ${ }^{8}$

$B^{2}-(1+\alpha-\beta) B+\alpha=0$.

The solution of this quadratic is the pair of roots, $B_{1}, B_{2}$, given by

$B_{1,} B_{2}=\frac{(1+\alpha-\beta) \pm \sqrt{(1+\alpha-\beta)^{2}-4 \alpha}}{2}$.

When the roots are real, the solution to the difference equation contains a linear combination of these roots in the form

$P_{t}=A_{1}\left(B_{1}\right)^{t}+A_{2}\left(B_{2}\right)^{t}+C$,

where $A_{1}, A_{2}$, and $C$ are constants.

When the roots are complex, the solution is in the form

$P_{t}=A r^{t} \cos (\theta t+\omega)+C$,

where $A, C$, and $\omega$ are constants that depend on the initial conditions (see Appendix A), $r=\sqrt{\alpha}$ and $\cos \theta=(1+\alpha-\beta) / 2 \sqrt{\alpha}$.

${ }^{8}$ The solution of difference equations is described in most mathematical economics texts. See, for example, Chiang (1984) or Sysdaeter and Hammond (1995). 


\section{Oscillations}

When the roots are complex, that is, when

$(1+\alpha-\beta)^{2}<4 \alpha$,

oscillations or cycles will occur. Therefore, in $\alpha, \beta$ parameter space when the $\alpha, \beta$ pairs satisfy (7), prices will exhibit oscillatory behavior (overshooting). Otherwise, price changes will be damped (no overshooting).

\section{Stability of Equilibrium}

Stability of equilibrium requires that the moduli of the roots, $B_{1}, B_{2}$, both be less than one. See Appendix A for more detail. With the restrictions from the economics of the problem, a necessary condition for convergence to equilibrium is that the absolute value of serial correlation, $\alpha$, is less than one.

$|\alpha|<1$.

Conditions (7) and (8) divide the parameter space into four regions. Figure 1 summarizes the analysis graphically in the $\alpha, \beta$ parameter space. In the figure,

Figure 1 The dynamic behavior of the difference equation. This graph illustrates the parameter values that generate the various dynamic patterns when equilibrium is shocked. Values of the autocorrelation coefficient greater than 1 result in divergent or explosive behavior. Parameter values that lie above the curved line result in oscillations or cycles (overshooting).

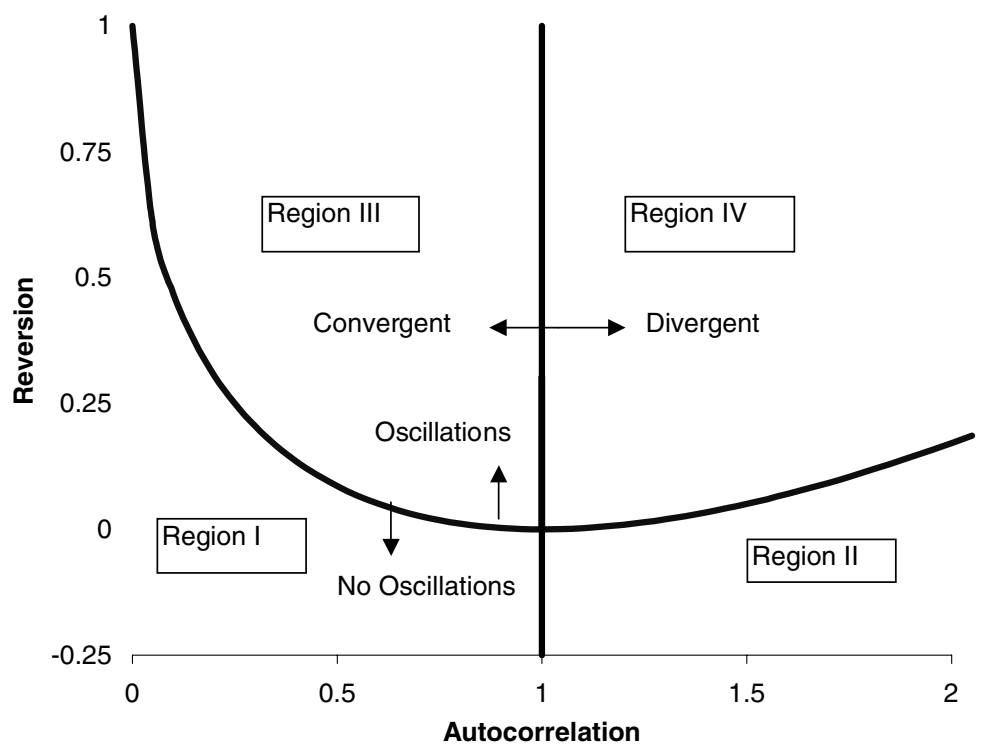


Figure 2 a Time-series behavior in the four regions. The panels illustrate the time-series behavior of the difference equation in the four regions in response to a ramp change (solid line) in the equilibrium house price $\left(P^{*}\right)$. The dotted lines represent the actual house price movement after the ramp change in the equilibrium from 100 to 110 in period zero. The regions correspond to the designations in Figure 1. A subcase of Region I occurs when alpha is less than one. In this case there is convergent alternation in a sawtooth pattern as the negative serial correlation causes values to alternate yearly.
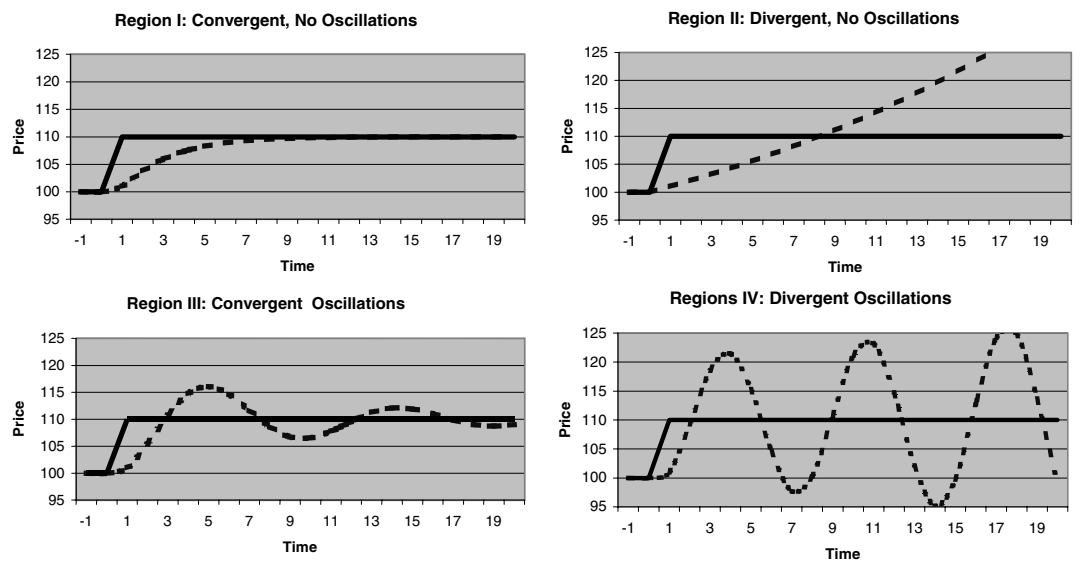

the curve defined by (7) separates cases without oscillations below the curve from parameter pairs with fluctuations above the curve.

The vertical line at $\alpha=1$ divides the parameter space into a divergent or explosive region to the right of the line and a convergent region to the left. When the autocorrelation coefficient is above unity, deviations from steady state are magnified over time and the path of values diverges from long-run equilibrium.

The two curves divide Figure 1 into four regions. Figure 2 summarizes the types of dynamic behavior that arise in each of the four regions in response to a ramp change in $P^{*}$. A subcase of region one occurs when serial correlation, $\alpha$, is negative. In this subcase, price converges without oscillations but in a two-period sawtooth alternating pattern caused by the negative autocorrelation.

\section{Amplitude}

When there are oscillations, the amplitude is given by

$$
A r^{t}=2\left(P^{*}-P_{0}\right) \sqrt{\frac{\alpha \beta}{4 \alpha-(1+\alpha-\beta)^{2}}}(\sqrt{\alpha})^{t} .
$$


At the first cyclical peak, which occurs approximately at $t=-\omega / \theta$, the amplitude is increasing in $\alpha$ and $\beta$ over the relevant economic ranges.

\section{Frequency}

The frequency of oscillations (equal to one over the period from peak to peak) is given by

$$
\frac{\theta}{2 \pi}=\frac{\arccos \left(\frac{(1+\alpha-\beta)}{2 \sqrt{\alpha}}\right)}{2 \pi},
$$

which is ambiguous in $\alpha$ and increasing in $\beta$. Figure 3 illustrates this relationship of frequency and amplitude at the first peak with the correlation and reversion parameters.

Intuitively, the solution, (6b), in the cases with oscillations is composed of sinusoidal oscillations between minus one and plus one with a frequency given by $\theta$ and a phase angle or time shift given by $\omega$. The amplitude of the oscillations is determined by $A \alpha^{t / 2}$, which decays or grows depending on whether $\alpha$ is less or greater than one. From (9) we also see that $A$ depends on how far from equilibrium the system starts, $\left(P^{*}-P_{0}\right)$, and the correlation and reversion parameters.

\section{Extensions}

A number of natural extensions of this analysis are possible but beyond the scope of this research. In the analysis of the dynamics we assumed that $P^{*}$ is a constant when in reality it is stochastic. If the fluctuations in $P^{*}$ have a frequency component, for example, because there is a national business cycle driving the fluctuations in $P^{*}$, then the frequency component in $P^{*}$ may reinforce or interfere with the local movements in the price $P_{t}$. When the fluctuations reinforce, the apparent fluctuations at the local level can be much larger.

It has also been assumed in (2) that the serial correlation acts on the entire past change in price. This implicitly assumes that in an urban area that grows at an above average rate for an extended period of time, participants do not anticipate the steady price increases. An alternative assumption might be to have the serial correlation act only on the unexpected component of price change. ${ }^{9}$

\footnotetext{
9 Another possible extension would be to consider asymmetric responses. This was investigated by Malpezzi (1999), who did not find evidence of asymmetries.
} 
Figure 3 a Frequency and amplitude at the first peak. The graphs illustrate the relationship between frequency and amplitude and the correlation and reversion parameters $\alpha$ and $\beta$. Frequency rises steeply with $\beta$ but is ambiguous in $\alpha$. The amplitude at the first peak, on the other hand, is rising steeply with serial correlation, $\alpha$, and rising slowly with mean reversion, $\beta$.

\section{Frequency}

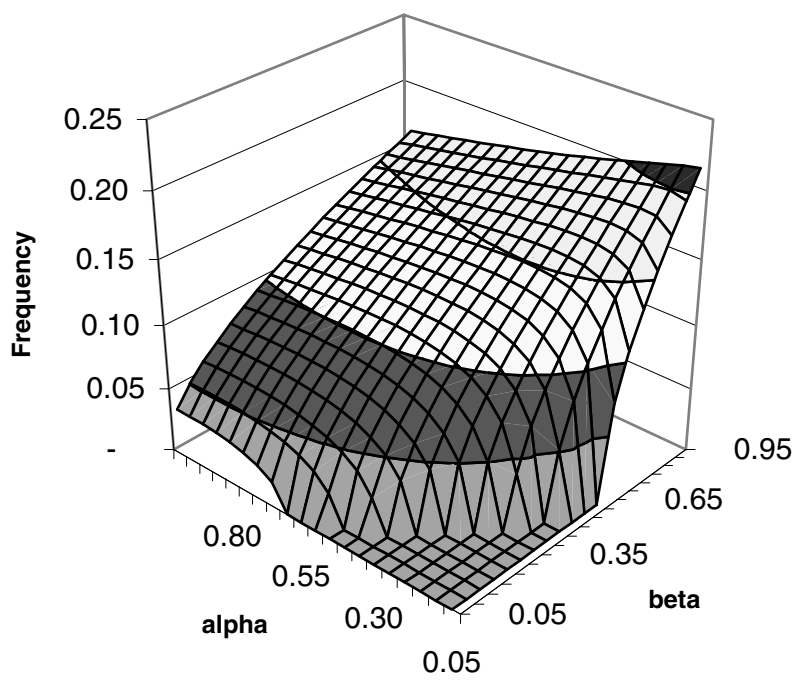

Amplitude at the First Peak

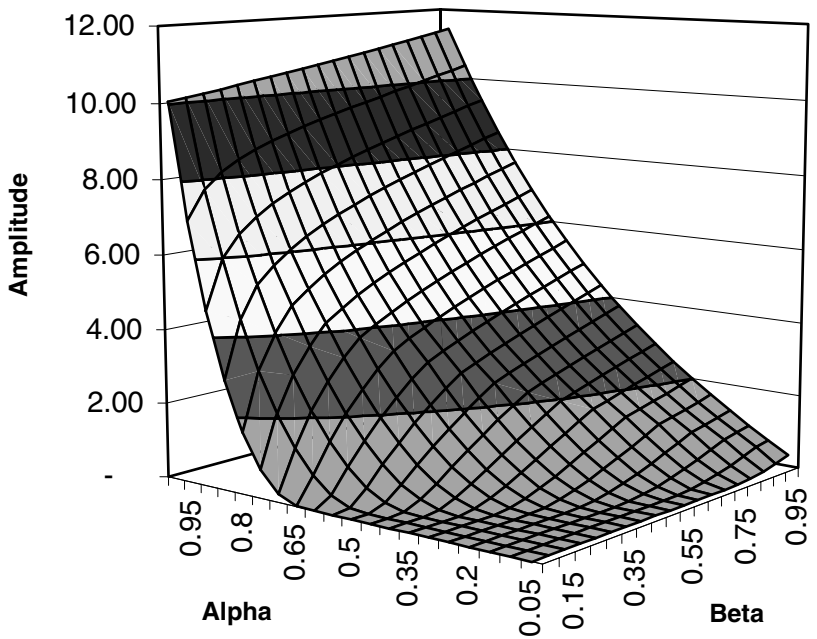




\section{The Hypotheses}

Our goal is to explore the causes of differences in the dynamic response of metro areas to shocks to the local economy. In the context of the model, these differences will appear as different estimates of $\alpha$ and $\beta$. Therefore we rewrite (2) as

$$
\begin{aligned}
\Delta P_{k t}= & \left(\sum_{i} \alpha_{i}\left(Y_{k i t}-\bar{Y}_{i}\right)\right) \Delta P_{k, t-1} \\
& +\left(\sum_{i} \beta_{i}\left(Y_{k i t}-\bar{Y}_{i}\right)\right)\left(P_{k, t-1}^{*}-P_{k, t-1}\right)+\gamma \Delta P_{k t}^{*},
\end{aligned}
$$

where $i$ indexes the variables and $k$ indexes cities, where $Y_{i}$, which may include a subset of the $\boldsymbol{X}$ and a unit vector, are independent variables, and where $\bar{Y}_{i}$ represents the mean value of $Y_{i}$ in the sample.

An important issue is the choice of the $Y_{i}$. A well-developed behavioral theory for correlation and reversion does not exist in urban economics, but there are a number of reasons to expect the adjustment to depend on information costs, supply costs and constraints, and expectations. ${ }^{10}$

\section{Information Costs}

First consider the role of information dissemination. In real estate markets, information costs are high, transactions are infrequent, and the product is highly heterogeneous. As a result, participants have difficulty assessing the current value of properties and may have to use sales distant in time or location for setting reservation prices (Quan and Quigley 1991). Markets with a higher level of transactions have lower information costs; thus, prices should adjust more quickly to their long-run equilibrium value, that is, mean reversion should be greater. Clapp, Dolde and Tirtiroglu (1995) argue that information costs will be lower the greater the number of transactions per unit area. Thus both population and population density, which are highly correlated, seem relevant. We include metro area population as a proxy for the number of transactions.

Another measure of the importance of information derives from models of search in housing markets (Wheaton 1990, DiPasquale and Wheaton 1996). In these models, a positive real income shock causes existing homeowners to be underhoused and thus, to move or renovate to increase their housing consumption to the new equilibrium levels. When transactions volume increases,

\footnotetext{
${ }^{10}$ In Equation $\left(2^{\prime}\right)$ we have assumed that $\gamma$ is not endogenous. Allowing for endogeneity would affect the amplitude but not the frequency.
} 
search costs decline and the reservation price for both buyers and sellers increases. Once the adjustment to new housing needs has occurred, transactions volume falls back to its long-run level. In terms of our model, higher real income growth should proxy for higher transactions volume and lower search costs, which should lead to faster mean reversion.

\section{Supply Costs}

A second set of hypotheses relate to the real cost of new housing. We identify possible cost effects both within a given market and across markets. Within a given urban area, when construction costs are high relative to the price of the existing stock, builders will have less incentive to add to supply until unit prices rise above the cost of new supply. Price increases will be more persistent since new supply is not available to ameliorate price increases until existing prices rise above the cost of new construction. We include the R.S. Means construction cost series for each metro area as a metric for construction costs. This series measures the labor and materials cost of construction.

Across different markets, high real construction costs vary not only because of materials and labor costs but also with unpriced supply restrictions. Regulation is an example of one such restriction. Stricter regulations on new development such as minimum lot size or regulatory-induced delays have two effects: They increase the cost of new housing (both in absolute terms and relative to existing housing) and they reduce the ability of builders to respond quickly to demand shocks. Mayer and Somerville (2000) show that construction is less responsive to price shocks in markets with more local regulation.

As proxies for supply restrictions we include a land supply index (Rose 1989) that measures the availability of land within the urban circumference. Our metrics for regulation include measures of use fees and total fees payable by developers and average and maximum times needed in the approval process.

In the context of our model, we hypothesize that higher real construction costs are correlated with slower mean reversion and more serial correlation. New supply can reduce the degree of serial correlation because, in the absence of a futures market, it is one way that participants can arbitrage inefficient pricing. In markets where supply can respond quickly to price shocks, serial correlation should be lower. We expect the regulatory variables to have a similar effect.

\section{Expectations}

Finally, we look for evidence of "euphoria" (Capozza and Seguin 1996), or backward-looking expectations, as an indicator of the degree of serial 
correlation. Case and Shiller $(1988,1989)$ and Shiller (1990) posit that serial correlation in real estate markets is partially due to backward-looking expectations of market participants. Case and Shiller (1988) have conducted surveys of recent buyers, showing that buyers in booming markets have greater expected house price appreciation than buyers in a control market. Buyers in the booming market indicate that they treat the purchase of a home more as an investment and discuss housing market changes more frequently. By contrast, buyers in the control market spend less time discussing the housing market and place more weight on the consumption value of a home, as opposed to its investment value. To the extent that these expectations are incorporated into observed transaction prices, strong markets should have more serial correlation than markets with slower growth. We include real income growth as an indicator of the state of the economic cycle. Long-run population growth is included to measure the role of inertia or backward-looking expectations in serial correlation.

To summarize, higher real income and population growth and a high level of real construction costs and regulation are expected to increase serial correlation. Higher real income growth, larger metro area size (population) and a lower level of real construction costs/regulation should increase mean reversion. This, of course, is not an exhaustive list of all the possible channels through which the dynamics might vary; rather, it should be viewed as an exploratory and illustrative list that allows verification that the correlation and reversion parameters can vary over time and over space in systematic ways.

\section{Data}

Our data are a subset of the large panel data set described in Capozza, Kazarian and Thomson (1997). The data for this study cover 62 metro areas for the 17 years from 1979 to 1995 . Included among the variables are median house prices, population, personal income, real construction costs, a land supply index, the consumer price index, mortgage rates, property tax rates and income tax rates. The data are annual series with the exception of income tax rates, which derive from the decennial census. The land supply index, a measure of the percentage of the land in the city that is available for development, also varies across urban areas, but not over time. ${ }^{11}$ Table 1 provides summary statistics on the data series.

The source and definition of all the variables appear in Appendix B. The metropolitan areas included in the study are listed in Appendix C.

${ }^{11}$ See Rose (1989) and Capozza and Seguin (1996) for more detail on this variable. 
Table 1 @ Summary statistics.

\begin{tabular}{lllll}
\hline \hline & Mean & $\begin{array}{l}\text { Standard } \\
\text { Deviation }\end{array}$ & Minimum & Maximum \\
\hline Real Price in 1990 dollars & 72,000 & 27,000 & 41,000 & 210,000 \\
Change in real price & $0 \%$ & $5 \%$ & $-14 \%$ & $29 \%$ \\
Population & $2,300,000$ & $3,100,000$ & 370,000 & $20,000,000$ \\
5-year change in population & $7 \%$ & $7 \%$ & $-6 \%$ & $31 \%$ \\
Real personal income & 13,900 & 2,200 & 7,700 & 22,000 \\
Change in real personal income & $1 \%$ & $2 \%$ & $-7 \%$ & $12 \%$ \\
Real construction cost index & 0.97 & 0.10 & 0.78 & 1.5 \\
User cost & $7.3 \%$ & $2.2 \%$ & $0.2 \%$ & $11 \%$ \\
Land supply index & 0.89 & 0.13 & 0.54 & 1 \\
\hline
\end{tabular}

\section{House Prices}

Two variables require more discussion. The first is the median house price series. There is considerable debate over the merits of using median house price data versus repeat sales data. This study uses the NAR median price series because of its long history and extensive coverage of metro areas. Repeat sales data were available at the regional level from the Federal Home Loan Mortgage Corporation (FHLMC) but for only a limited number of Metropolitan Statistical Areas (MSAs). The median and the repeat sales price series exhibit similar overall patterns, but there are timing differences, especially in the Northeast and the Southeast. The Pearson product-moment correlations of the price changes are $0.59,0.73,0.89,0.88$ and 0.92 for the Northeast, Southeast, North Central, Southwest and West regions, respectively. The correlations of first differences suggest there will not be a large difference between empirical estimates from the two data series. We report the results of a robustness check using the FHLMC data below.

Because our model estimates the long-run real house price level in the first stage, we take advantage of the level differences between metro areas obtained with median prices. Repeat sales indexes only measure relative prices within a city over time, but not across different cities. Thus, repeat sales data are not well suited for estimation procedures that attempt to exploit the cross-sectional variation by using the absolute dollar value of housing.

Neither median nor repeat sales data are fully quality adjusted. The upward quality drift in the median prices is about $2 \%$ per year (Hendershott and Thibodeau 1990) and occurs both because new houses of above average quality are added and because existing houses are renovated. In the typical metro area, much of the quality drift arises from renovations. Repeat sales data include only 
existing houses so that only the drift from renovations applies. Since typical repeat sales procedures attempt to exclude or adjust for houses that increase in size, the quality drift is mitigated. Many existing houses are renovated soon after purchase. For our purposes, a constant rate of upward drift will not affect the results since we include dummy variables for each year of the sample. A more important issue is systematic changes in the quality of the median house over an economic cycle. If the quality of the median house is systematically different near peaks than it is near troughs, then the median price series will over- or underestimate cyclical movements. However, as long as this bias is constant across cities, it will not impact our estimates of the factors that affect the cyclicality of prices. Nevertheless, the results should be interpreted with the appropriate caution.

\section{User Cost}

The user cost is a derived variable. It is an attempt to capture the after-tax cost of home ownership. Our calculation adjusts ownership costs for taxes, expected appreciation rates and maintenance and obsolescence (3\%):

User cost of capital $=($ Mortgage rate + Property tax rate $)$

$$
\times(1-\text { Income tax rate })-\text { Inflation rate }+0.03 \text {. }
$$

Two data issues are worth noting. First, only the tax rate metrics vary crosssectionally so that user cost is mainly a time-series variable. Mortgage rates and inflation rates are national series. Second, since the expected appreciation of housing is being measured by the national inflation rate (CPI) during the previous year, the variation in expectations by location, which may be substantial, is not incorporated. It can be argued since housing purchases are a long-horizon decision ( 7 years or more), a long-run expected appreciation rate should be used. Over long horizons housing prices have appreciated at rates remarkably close to the rate of inflation. Nevertheless, more sophisticated measures of expected appreciation and user cost are possible, but beyond the scope of this research. ${ }^{12}$

\section{Empirical Estimates}

Our empirics are developed in two stages. First, we estimate the proposed long-run equilibrium price relationship, Equation (1). Second, we estimate the adjustment relationships, Equation (2) or (2'), allowing for partial adjustment,

\footnotetext{
${ }^{12}$ For example, Capozza and Seguin (1996) have shown that current rent-to-price ratios are a significant conditioning variable when analyzing long-run (decadal) appreciation rates.
} 
serial correlation and mean reversion. When estimating $\left(2^{\prime}\right)$, the serial correlation and mean reversion coefficients vary over time and space.

In the econometrics literature, models with mean reversion are known as "error correction models" (ECMs). If an equation like (1) is indeed an equilibrium one, then we expect there to be a "cointegrating relationship" among the variables. To test for cointegration, it is typical in ECM estimation to apply unit root tests based upon Dicky-Fuller (DF) or augmented Dickey-Fuller (when lags are being estimated) or Phillips and Perron (1988). However, Levin and Lin (1993) suggest that such tests cannot be directly applied to panel data. Further, Pedroni (1997) suggests that the usual applications of DF are inappropriate in order to test for cointegration in a panel setting.

Given this context, researchers have followed various strategies. One approach (Malpezzi 1999, Gallin 2003) has been to relate house prices to income levels. Malpezzi rejects "the null for the estimated error in the house price to income cointegrating vector at the $1 \%$ level" (p. 46). Gallin, on the other hand, argues that even bootstrap methods cannot reject the hypothesis of no cointegration between house prices and income. He cautions that the "error-correction specification may be misleading" (p. 14).

Given the difficulty of testing for cointegration in panel data sets like ours, the approach we follow is to carefully relate Equation (1) to an equilibrium arising from urban theory. If the theory is correct, equilibrium will exist along with a cointegrating relationship among the variables. Thus, we are assuming that the cointegration tests can be met. Nevertheless, Gallin's caveat applies.

\section{Preliminaries: The Equilibrium Relationship}

We begin by fitting a long-run equilibrium equation for real house price levels in a metro area using the annual panel data described in the previous section. The equation is estimated in two versions, first, using OLS, and second, using a panel data estimator that controls for both year and metro area fixed effects. These fixed effects will capture any systematic differences in the average quality of housing across cities or over time.

As indicated above, our choice of variables, $\boldsymbol{X}$, is motivated by the equilibrium asset pricing model for a small open city in Capozza and Helsley (1989).

- Population-In equilibrium, larger cities have higher rents and prices to preserve intraurban locational equilibrium, that is, rent gradients shift up as metro areas grow. 
- Real Income - The unit of measurement for our dependent variable is one dwelling unit, whereas the theoretical unit of measurement is a unit of dwelling space (e.g., a square foot of living area). Since housing is income elastic, we expect residents of urban areas with higher incomes to consume more dwelling space, and consequently median prices per dwelling unit will be higher.

- Real Construction Cost-When vacant land is converted to urban uses, costly labor and materials must be used. The higher the costs for these items, the higher the price of the marginal dwelling.

- Urban Growth Rate-Capozza and Helsley (1989) show that land for conversion at the edge of an urban area has a premium above the opportunity cost in agriculture that depends on the growth rate of the area. When marginal land costs are higher, dwelling units will be more expensive on average, ceteris paribus.

- User Cost-Rents are related to prices through the capitalization rate or "user cost," as it is more commonly called in the housing literature. Interest rates, tax rates and expected appreciation rates all affect this composite variable.

- Land Supply Index-The land supply index measures the percentage of land that can be developed within the urban circumference surrounding the urban center. Urban areas located on a waterfront will be able to develop only a semicircle of land surrounding the center. For a given population, the length of the average commute will be longer; in equilibrium, the average house rent and price will be higher.

Estimates for this equation are given in Table 2. All variables in Model 1 of Table 2 have the expected sign, and many coefficients have the expected magnitude. In particular, real median house prices are positively related to total population, real median income, the index of real construction costs and the five-year growth rate in population (proxying for the long-run expected growth rate of population ${ }^{13}$ ), and they are negatively related to the user cost of housing and the land supply index. Many coefficients suggest reasonable elasticities. For example, the coefficient on real construction cost is 1.1 in Model 1 and 1.2 in Model 2 when fixed effects are included in the specification. Neither value is statistically different from the theoretical prediction of 1.03 at the $5 \%$ level. (The mean index value is 0.97 ; therefore, a 0.01 unit increase in the cost index leads to a $1.03 \%(=1 / 0.97)$ increase in prices. $)$

${ }^{13}$ Blanchard and Katz (1992) show that the growth rate of population is persistent over time using state-level data over several decades. 
Table 2 घ Steady state regression.

\begin{tabular}{lccccc}
\hline \hline & \multicolumn{2}{l}{ Model 1: OLS } & & \multicolumn{2}{c}{ Model 2: Fixed Effects } \\
\cline { 2 - 3 } \cline { 5 - 6 } \cline { 5 - 6 } & Coefficient & $T$-Statistic & & Coefficient & $T$-Statistic \\
\hline Log of population & 0.07 & 7.7 & & 0.15 & 2.9 \\
Log of real median income & 0.45 & 9.7 & & 0.43 & 5.3 \\
Real construction cost & 1.10 & 14.8 & & 1.20 & 13.9 \\
5-year \% change in population & 1.53 & 16.4 & & 1.54 & 13.9 \\
Log of user cost & -0.04 & -3.1 & & -0.09 & -03.2 \\
Land supply index & -0.38 & -7.6 & & \multicolumn{3}{c}{ Yes } \\
Fixed effects (city, year) & \multicolumn{3}{c}{ No } & & \multicolumn{3}{c}{0.43} \\
$R^{2}$ & \multicolumn{3}{c}{0.65} & & \\
\hline
\end{tabular}

Dependent variable is the $\log$ of real price. OLS estimates of Equation 1 in the text. Model 2 is estimated with fixed effects.

The coefficients on real income suggest that a $1 \%$ rise in a metro area's real income leads to almost a $0.5 \%$ increase in real median house prices. If we interpret the coefficient as an income elasticity, then consumers are buying about $5 \%$ more housing when incomes are $10 \%$ higher. This is consistent with, but at the lower end of, other estimates of income elasticities. ${ }^{14}$

The amount of developable land around a city, measured by the land supply index, has a negative and significant effect on the real price level, as would be expected. The regulatory variables were not significant and are not reported.

The real price elasticity with respect to city size (population) in Model 2 is 0.15 , which is smaller than would be obtained from a standard monocentric city urban model. However, the existence of multiple subcenters should lower the expected size of the population coefficient relative to a standard urban model. Long-run growth has a large impact on real price levels; a $1 \%$ increase in the population growth rate over the last 5 years leads to $1.5 \%$ higher real house price. Perhaps due to limited cross-sectional variation, the user cost coefficients of -0.04 and -0.09 are statistically different from zero, but they are far from the value of -1.0 predicted by theory. ${ }^{15}$ Model 2 does not include the land supply index because it is subsumed by the fixed effects.

\footnotetext{
${ }^{14}$ It is worth noting that this estimate is not consistent with a constant price-to-income ratio as is assumed in many studies, for example, Malpezzi (1999), Lamont and Stein (1999), Gallin (2003).

15 In a study using similar cities but decennial data only (1970, 1980 and 1990), Capozza, Green and Hendershott (1996) find a price elasticity of -0.8 , insignificantly different from -1.0 .
} 
Because $F$-tests of the significance of the time and metro area effects reject that these fixed effects equal zero at the 0.001 confidence level, we use fitted values from Model 2 in the second-stage regressions.

\section{Dynamics: The Adjustment Equation}

The second-stage analysis uses the estimates of $P^{*}$ from the first-stage equation to anchor the estimates of price changes. In particular, we estimate Equation (2) where $\alpha$ represents the degree of serial correlation, $\beta$ is the extent of mean reversion and $\gamma$ is the contemporaneous adjustment of prices to current shocks. If house prices adjusted instantaneously to local economic shocks and if real estate markets were perfectly efficient, then $\gamma$ would equal 1 and $\alpha$ would equal 0 (theory has no prediction about the estimated value of $\beta$ because actual house prices would never deviate from their long-run equilibrium). However, abundant academic research has shown that $\alpha$ is positive and economically and statistically significant. For example, Case and Shiller (1989) estimate that annual serial correlation in their sample of four cities ranges from 0.25 to $0.5{ }^{16}$ Abraham and Hendershott (1993) obtain an estimate of 0.4 on a panel of 29 cities. When the cities are divided roughly in half, the estimate is 0.5 for the coastal cities versus 0.2 for the inland cities (Abraham and Hendershott 1996). When house prices converge to their equilibrium values in the long run, $\alpha>0$ implies $\beta>0$.

Estimates from this second-stage equation are given in Model 1 of Table 3. To control for possible omitted local factors that might cause differential appreciation rates, we initially included fixed effects for all MSAs. The subsequent regressions do not include these fixed effects in the second stage because an $F$-test of the significance of these factors does not allow for rejection at conventional confidence levels and the empirical work is little changed by their exclusion.

The empirical results in Table 3, Model 1, are consistent with the previous real estate literature and suggest slow responses for real estate relative to more liquid assets like equities (Fama and French 1988). The immediate adjustment coefficient, $\gamma$, for example, suggests that current house prices adjust by $52 \%$ of the value of a shock to the equilibrium house price levels in the year of the shock. In addition, house prices also exhibit strong serial correlation, with

\footnotetext{
${ }^{16}$ Case and Shiller (1989) also note that the construction of repeat sales indexes induces spurious serial correlation in estimators derived from a single sample of houses. Such a bias does not affect our sample because we use median sales prices. Even with repeat sales indexes, however, spurious serial correlation would only bias the intercept in the third stage, not the coefficients on other explanatory variables.
} 
Table 3 a Second-stage price regressions.

\begin{tabular}{|c|c|c|c|c|c|c|}
\hline & \multicolumn{2}{|l|}{ Model 1} & \multicolumn{2}{|l|}{ Model 2} & \multicolumn{2}{|l|}{ Model 3} \\
\hline & Coefficient & $T$-Statistic & Coefficient & $T$-Statistic & Coefficient & $T$-Statistic \\
\hline Change in the first stage fitted & 0.52 & 13.2 & 0.53 & 13.9 & 0.53 & 13.9 \\
\hline Lagged change in real price & 0.33 & 12.2 & 0.49 & 1.8 & 0.49 & 1.2 \\
\hline Change in population times lagged real price change & & & 4.79 & 2.3 & 5.04 & 2.4 \\
\hline Change in real income times lagged real price change & & & 5.02 & 4.2 & 5.05 & 4.2 \\
\hline Real construction cost times lagged real price change & & & 1.47 & 6.1 & 1.62 & 6.0 \\
\hline Land supply index times lagged real price change & & & & & 0.27 & 1.2 \\
\hline Deviation from steady state & 0.25 & 13.1 & 0.26 & 1.7 & 0.27 & 1.6 \\
\hline Log population times deviation from steady state & & & 0.06 & 2.4 & 0.06 & 2.3 \\
\hline Change in real income times deviation from steady state & & & 1.40 & 1.7 & 1.43 & 1.8 \\
\hline Real construction cost times deviation from steady state & & & -0.40 & -1.8 & -0.39 & -1.8 \\
\hline$R^{2}$ & \multicolumn{2}{|c|}{0.42} & \multicolumn{2}{|c|}{0.49} & \multicolumn{2}{|c|}{0.46} \\
\hline
\end{tabular}

Dependent variable is the percent change in real housing price. Ordinary least squares estimates of Equation (6) in the text with steady-state values estimated from Model 2 of Table 1. 
a coefficient of 0.33 . This estimate is consistent with those in Abraham and Hendershott (1996) and Case and Shiller (1989). Furthermore, our estimates show that the other $48 \%$ of house price adjustment occurs only gradually over time. Actual prices converge only $25 \%(=\beta)$ of this difference every year. This estimate is greater than that of Abraham and Hendershott (1996) who report a $\beta$ of 0.1 for cities on the coasts (e.g., Boston, New York, San Francisco, Los Angeles) but zero for cities in the Midwest (e.g., Chicago, Milwaukee, Cleveland, Detroit). In the next section, we allow for variation in $\alpha$ and $\beta$ over both time and location.

\section{Endogenous Dynamic Adjustment}

In Table 3, Model 2, we estimate possible determinants of serial correlation and mean reversion by interacting variables derived from the hypotheses described earlier-information dissemination (population growth), search costs (real income growth) and supply costs and restrictions (real construction costs, land supply index) - with the serial correlation and mean reversion parameters, as in Equation $\left(2^{\prime}\right)$. That is, serial correlation and mean reversion are allowed to vary both over time and over space.

These estimates, presented in Models 2 and 3 in Table 3, provide significant evidence consistent with all three of the hypotheses. The most striking results are the determinants of serial correlation. High real construction costs and faster growth in both population and real income are associated with greater autocorrelation. A one standard deviation change of $2 \%$ to either real income or the 5-year growth rate of population leads to a $10 \%$ increase in serial correlation (a third of the overall effect in Model 1). Both of these results suggest that house prices exhibit much more serial correlation, and thus a greater likelihood of overshooting their long-run equilibrium values, in metro areas in the midst of strong economic expansions.

Differences across MSAs in real construction costs lead to economically and statistically significant differences in serial correlation. For example, an increase in real construction costs of $10 \%$ would increase serial correlation by 15 percentage points - one-half of the average serial correlation coefficient in Model 1. To the extent that high construction costs are related to inelastic supply, the costs may be indicative of factors that do not allow the supply of new houses to adjust quickly to demand shocks. Regulation and geography are two examples of such factors. Many types of land use regulation raise development costs and make it more difficult for developers to respond to market signals. Mayer and Somerville (2000), for example, show that higher levels of regulation lead to fewer permits and lower supply elasticities. Reduced land availability, either because of historic development or small farms at the periphery of an urban area, may make land assembly more difficult and expensive. 
In Model 3, we explore the extent to which geography (the land supply index) is related to the construction cost result reported earlier. However, the coefficient on the land supply interaction is the opposite of that predicted by theory and not statistically significant. Similarly, our experiments (not reported in the table), with regulatory variables like use fees and time to approval, proved to be unrewarding.

While the results on the impact of various factors explaining the degree of mean reversion are consistent with the hypotheses, they are weaker in terms of economic and statistical significance. The interaction coefficients are statistically significant at the 5 or $10 \%$ levels.

Metro area size is positively related to the degree of mean reversion, an effect that would be predicted from search models with imperfect information. Information about demand shocks is easier to discern in thicker markets in which comparable units sell more often. Thus prices should adjust more quickly to their equilibrium levels because homeowners can more easily determine a price for a house that incorporates latest market information. The estimates show that prices revert to their mean six percentage points faster in a metro area that is twice as large as a comparison metro area.

Also consistent with search models, higher income growth leads to greater mean reversion. As with population, the economic impact of differences in income growth is moderate. A two percentage point increase in the growth rate of income leads to a $3 \%$ increase in mean reversion (10\% of the total effect). Finally, a $10 \%$ increase in real construction costs lowers mean reversion by four percentage points.

\section{Robustness Tests}

In addition to the specifications reported above, a number of alternative specifications were tried but not reported in the tables. These include alternatives using the available repeat sales price data as the dependent variable in the stage 1 and 2 regressions. The results were quite economically similar for the equations in Table 2, but with smaller sample sizes there is less statistical significance for the independent variables. In the second-stage regressions, the repeat sales data exhibit more serial correlation ( 0.55 vs. 0.33 ) and less mean reversion ( 0.15 vs. 0.25 ), suggesting the likelihood of greater overshooting.

As indicated earlier, alternative panel error specifications were also tried and tested against the models presented. Finally, because of the importance of supply in the stage 2 regressions, additional variables on the regulatory structure for housing supply were compiled and tested. These variables include data on local fees payable by developers (use fees and total fees) as well as the average 
and maximum times needed in the approval process. None of these regulatory variables was statistically significant at the usual levels in the stage 2 regressions. Since casual empiricism leads us to believe that supply restrictions play a significant role in the evolution of house prices, these negative results were a disappointment. The negative results are consistent with either inadequate data metrics or with no relationship. We lean towards the former explanation and expect that as better data become available, a significant relationship with supply restrictions will be found.

\section{How Do the Estimates Relate to the Dynamics Defined by the Difference Equations?}

The implication of Model 2 in Table 3 is that for each time period and for each metro area, the dynamics will vary depending on the realizations of the exogenous variables. What do the fitted values for the 992 usable observations tell us about the possible dynamics?

Figure 4 summarizes the results. It plots the autocorrelation and mean reversion coefficients for each city in each year and is superimposed on Figure 1. Several items are worth noting. First, the realizations are spread over three of the four regions defined earlier and encompass both damped and oscillatory and both convergent and divergent behavior.

Second, two-thirds of the realizations lie in the damped cyclical region (III; see Table 4). Therefore, we can expect damped oscillations to be the most common reaction to price shocks. Another $26 \%$ fall into Region I, the convergent, no oscillation region.

Third, the remaining 69 realizations, or $7 \%$ of the cases, lie in the divergent range where serial correlation is greater than 1 . Twelve of the metro areas $(20 \%)$

Table 4 Distribution of fitted parameters for correlation and reversion.

\begin{tabular}{lr}
\hline \hline Region & Percent \\
\hline Region I, Convergent, No Oscillation & $26 \%$ \\
Subregion IA, Convergent Alternation & $4 \%$ \\
Region II, Divergent, No Oscillation & $0 \%$ \\
Region III, Convergent Oscillation & $67 \%$ \\
Region IV, Divergent Oscillation & $7 \%$ \\
Total & $100 \%$ \\
\hline
\end{tabular}

This table lists the percentage of fitted observations in each of the regions defined in Figure 1. 
Figure 4 a Parameter realizations. This figure superimposes the fitted values (Table 3, Model 2) for the serial correlation and mean reversion parameters for each of the 992 metro area and year observations onto the parameter space plot (Figure 1). The mean values for correlation and reversion, 0.47 and 0.23 , respectively, lie solidly inside Region III, the damped cyclical region. However, the fitted values span three of the four regions. Seventy observations have correlations exceeding one and lie in the divergent range.

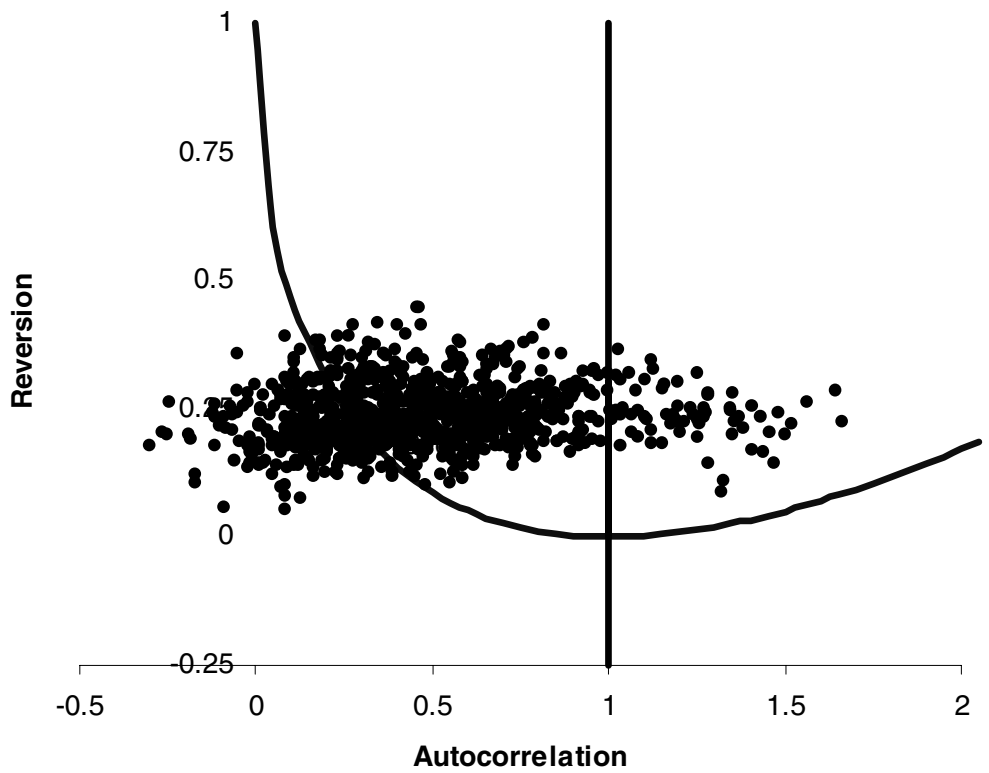

have at least one realization in this divergent range. The metros in this group are rapidly growing metros like Las Vegas, Riverside/San Bernardino and West Palm Beach rather than the large metros like Boston and San Francisco that have been associated with large price changes in recent years. Large price changes, of course, can arise from either demand shocks and/or from parameters in the divergent range. ${ }^{17}$

Finally, we note that the variation in the fitted serial correlation is greater than the variation in the mean reversion parameter. While the mean reversion coefficient varies only between about -0.05 and -0.45 , the autocorrelation coefficient varies from about -0.2 to 1.7 or about five times as much.

\footnotetext{
17 The largest three-year changes in the estimated equilibrium price occurred in the central part of the country during the sample period. Among the ten largest are Houston, Tulsa, Albuquerque, Oklahoma City, Birmingham and Portland in the 1980s and Denver and Riverside/San Bernardino in the 1990s.
} 
Figure 5 - Dynamic behavior at the sample estimates. This figure illustrates the dynamic behavior for values of the parameters at the sample estimates in Table 3, Model 2. The pattern is convergent and oscillatory at these estimates. Prices overshoot by about $20 \%$ of the shock to the equilibrium value, $P^{*}$, at time 1 . The period of the oscillations is 5.6 years. The parameter values used to generate the graph are $\alpha=0.49, \beta=0.26$ and $\gamma=0.53$.

\section{Alpha $=.49$, Beta $=.26$}

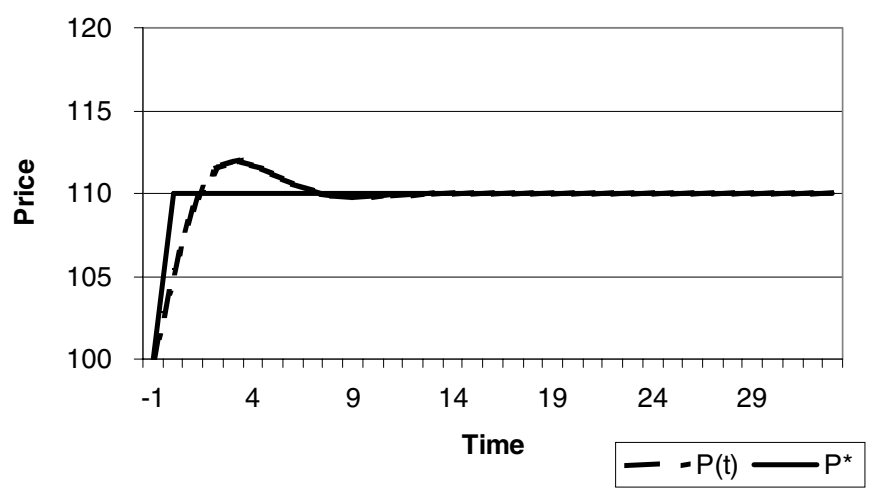

The typical dynamic pattern when the parameters are set to their average fitted values from Table 3, Model $2(\alpha=0.49, \beta=0.26, \gamma=0.53)$ is depicted in Figure 5. The pattern is convergent and oscillatory with a period of 5.6 years. By year 4, prices overshoot the change in the equilibrium, $P^{*}$, by about $20 \%$. The oscillations dampen rapidly after this first cycle.

Figure 6 plots the time-series patterns arising when the correlation and reversion parameters are one standard deviation above and/or below their estimated means. When the correlation parameter is high and reversion low, the timeseries pattern is still convergent but with much more persistent oscillations. When the correlation parameter is low and the reversion high, the pattern is convergent without oscillations. For more extreme values of the correlation parameter (two standard deviation changes) the pattern can become divergent oscillations (Region IV) or convergent alternation (Region I with negative $\alpha$ ).

\section{Conclusion}

In this research we link empirical estimates of serial correlation and mean reversion to the implied difference equation. We analyze and categorize the dynamics of the difference equation and relate the basic features like amplitude and frequency to the correlation and reversion parameters. The analysis 
Figure 6 - Dynamic behavior at the sample estimates plus/minus one standard deviation. The two panels illustrate the dynamic behavior for values of the parameters at the sample estimates in Table 3, Model 2, plus/minus one standard deviation. The parameters values for the first panel are $\alpha=0.80, \beta=$ 0.18 and $\gamma=0.53$. The parameter values used to generate the lower graph are $\alpha=0.15, \beta=0.29$ and $\gamma=0.53$. The two graphs illustrate the wide range of dynamics encompassed by the range of estimates.

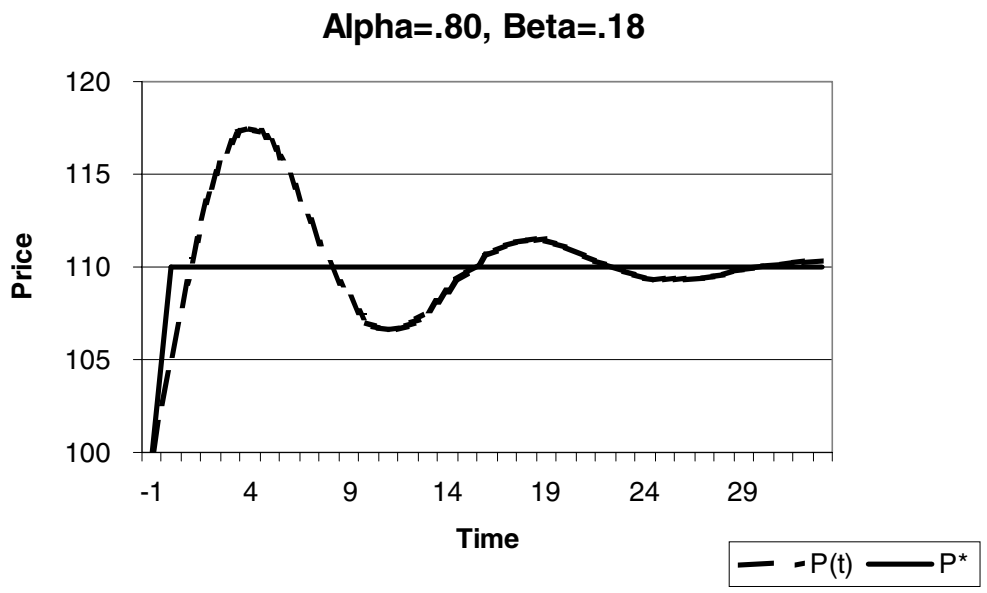

Alpha $=.15$, Beta $=.29$

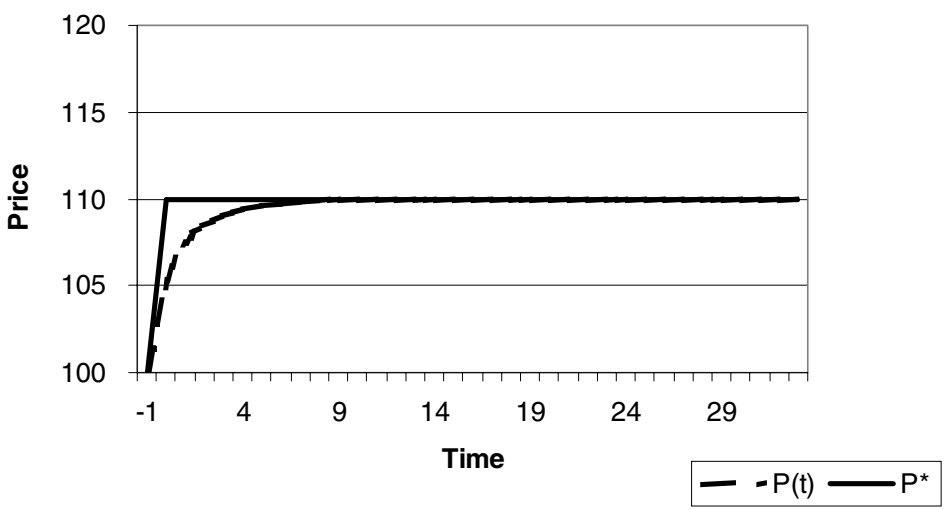

provides a specific definition for "cycles" and "bubbles" in the context of the standard model and relates the possible dynamic patterns to the required correlation and reversion parameters. We are able to identify the correlation and reversion parameters under which the dynamic responses to shocks will be convergent (stable) or divergent (e.g., "bubbles") and damped or oscillatory (i.e., "overshooting or cycles"). 
We then estimate the correlation and reversion parameters allowing the parameters to vary with proxies for information costs, supply costs and expectations. That is, in the estimates, the correlation and reversion parameters can vary by location and over time. The resulting average parameter values fall in the region of convergent oscillations. Estimates for specific observations range over three of the four defined regions. Two-thirds of the observations lie in the convergent oscillations regions (III). Another 26\% fall in the convergent, no oscillation region (I). The remaining 7\% are in Region IV with divergent oscillations.

Our results show that variation in the behavior of house prices across metropolitan areas is due to more than just a common behavioral reaction to different economic shocks. House prices react differently to economic shocks depending on such factors as information costs, supply costs and expectations.

The correlation and reversion parameters are found to vary substantially among metro areas. While the average metro area in the sample has an autocorrelation coefficient of 0.49 , an area with a zero growth rate of population and real income and relatively low construction costs (index $=0.90$ ) would have an autocorrelation coefficient of just 0.23 . An area with $4 \%$ growth in population and real income and high real construction costs (index $=1.04$ ) would have a coefficient of 0.75 . Similar types of variation in metro area size (5 vs. 10 million people) and real income growth rates (0 vs. $4 \%$ ) would lead to differences in mean reversion of 18 to $30 \%$, with the latter occurring in large, high real income growth cities. Thus, information costs and supply costs appear to have a large impact on the reaction of a metro area to shocks in the equilibrium price.

High real income growth boosts serial correlation and mean reversion, although the former about three times as much as the latter. High construction costs, on the other hand, raise correlation and lower reversion. High serial correlation can cause house prices to rise significantly beyond their equilibrium and eventually to a decline in prices. Therefore, this evidence is consistent with the behavior of house prices in markets such as Boston and New York in the 1980s, which had large increases in real incomes coupled with high construction costs over this period.

This research is exploratory and highlights a number of areas where additional study is needed. Future research could address the possible extensions to the dynamic analysis as well as the micro foundations for the behavior of individuals and markets, particularly the role of regulation, liquidity, information and psychology.

We thank Charles Anderson, Tom Thibodeau, the reviewers and the participants in seminars at Columbia University, the University of Michigan and the ASSA meetings 
for helpful comments. Ryan Israelsen provided able research assistance. The usual disclaimer applies.

\section{References}

Abraham, J. and P.H. Hendershott. 1993. Patterns and Determinants of Metropolitan House Prices, 1977-91. Real Estate and the Credit Crunch. Proceedings of the 25th Annual Federal Reserve Bank of Boston Conference. L.E.Browne and E.S. Rosengreen, eds. Blackwell: Boston.

7: 191-207.

Blanchard, O. and L. Katz. 1992. Brookings Papers on Economic Activity. The Brookings Institution: Washington DC.

Capozza, D.R., R. Green and P.H. Hendershott. 1996. Taxes, Home Mortgage Borrowing and Residential Land Prices. Fundamental Tax Reform. H.J. Aaron and W.G. Gale, eds. The Brookings Institution: Washington DC.

Capozza, D.R. and R. Helsley. 1989. The Fundamentals of Land Prices and Urban Growth. Journal of Urban Economics 26: 295-306.

Capozza, D.R., D. Kazarian and T. Thomson. 1997. Mortgage Default in Local Markets. Real Estate Economics 26: 631-656.

Capozza, D.R., C. Mack and C. Mayer. 1997. The Dynamic Structure of Housing Markets. Working paper. University of Michigan.

Capozza, D.R. and P.J. Seguin. 1996. Expectations, Efficiency, and Euphoria in the Housing Market. Regional Science and Urban Economics 26: 369-386.

Case, K.E. and R.J. Shiller. 1988. The Behavior of Home Buyers in Boom and PostBoom Markets. New England Economic Review November/December: 29-46.

1989. The Efficiency of the Market for Single Family Homes. The American Economic Review 79: 125-137.

Chiang, A.C. 1984. Fundamental Methods of Mathematical Economics, 3rd ed. McGraw-Hill: New York.

Chiang, R., I. Davidson and J. Okunev. 1997. Some Further Theoretical and Empirical Implications Regarding the Relationship between Earnings, Dividends and Stock Prices. Journal of Banking and Finance 21: 17-35.

Clapp, J.M., W. Dolde and D. Tirtiroglu. 1995. Imperfect Information and Investor Inferences from Housing Price Dynamics. Real Estate Economics 23: 239-270.

DiPasquale, D. and W. Wheaton. 1996. Urban Economics and Real Estate Markets. Prentice-Hall: Englewood Cliffs, NJ.

Fama, E. and K. French. 1988. Permanent and Temporary Components of Stock Prices. Journal of Political Economy 96: 246-273.

Frankel, J. and A. Rose. 1996. A Panel Project on Purchasing Power Parity: Mean Reversion within and between Countries. Journal of International Economics 40: 209224.

Gallin, J. 2003. The Long-Run Relationship between House Prices and Income: Evidence from Local Housing Markets. Federal Reserve Board: Washington, DC.

Hendershott, P.H. and T. Thibodeau. 1990. The Relationship between Median and Constant Quality House Prices: Implications for Setting FHA Loan Limits. Journal of the American Real Estate and Urban Economics Association 18: 323-334.

Hong, H., T. Lim and J.C. Stein. 2000. Bad News Travels Slowly: Size, Analyst Coverage, and the Profitability of Momentum Strategies. Journal of Finance 55(1): 265-295. 
Lamont, O. and J. Stein. 1999. Leverage and House Price Dynamics in U.S. Cities. RAND Journal of Economics 30: 498-514.

Levin, A.C. and C.F. Lin. 1993. Unit Root Tests in Panel Data: Asymptotic and Finite Sample Properties. Mimeo. University of California, San Diego.

Malpezzi, S. 1999. A Simple Error Correction Model of Housing Prices. Journal of Housing Economics 8: 27-62.

Mayer, C. and T. Somerville. 2000. Land Use Regulation and New Construction? Regional Science and Urban Economics 30(6): 639-662.

Meen, G. 2002. The Time-Series Behavior of House Prices: A Transatlantic Divide? Journal of Housing Economics 11: 1-23.

Pedroni, P. 1997. Panel Cointegration: Asymptotic and Finite Sample Properties of Pooled Time Series Tests with an Application to the PPP Hypothesis: New Results. Working Paper. Indiana University: Bloomington.

Phillips, P.C.B. and P. Perron. 1988. Testing for a Unit Root in Time Series Regressions. Biometrika 75: 335-346.

Poterba, J. and L. Summers. 1988. Mean Reversion in Stock Prices: Evidence and Implications. Journal of Financial Economics 22: 27-59.

Quan, D.C. and J. Quigley. 1991. Price Formation and the Appraisal Function in Real Estate Markets. Journal of Real Estate Finance and Economics 4: 127-146.

Rose, L.A. 1989. Urban Land Supply: Natural and Contrived Restrictions. Journal of Urban Economics 25: 325-345.

Shiller, R. 1990. Market Volatility and Investor Behavior. The American Economic Review 80: 58-62.

Sysdaeter, K. and P.J. Hammond. 1995. Mathematics for Economic Analysis. PrenticeHall: Princeton, NJ.

Wheaton, W.C. 1990. Vacancy, Search, and Prices in a Housing Market Matching Model. Journal of Political Economy 98: 1270-1292.

\section{Appendix A: Solution and Stability of Equilibrium for the Difference Equation}

\section{Solution}

Let $P_{t}^{*}=P^{*} \forall t$ and $P_{0} \neq P^{*}$. Then the difference equation, (2), can be written:

$P_{t}-(1+\alpha-\beta) P_{t-1}+\alpha P_{t-2}=\beta P^{*}$.

\section{Initial Conditions}

Let

$P(0)=P_{0}$,

Then,

$P(1)=P_{0}+\beta\left(P^{*}-P_{0}\right)$. 
The roots of the characteristic equation are

$B_{1}, B_{2}=\frac{(1+\alpha-\beta) \pm \sqrt{(1+\alpha-\beta)^{2}-4 \alpha}}{2}$.

Case 1. $(1+\alpha-\beta)^{2}>4 \alpha$ (Distinct Real Roots):

$P_{t}=A_{1} B_{1}^{t}+A_{2} B_{2}^{t}+P^{*}$,

where

$A_{1}, A_{2}=\frac{\left(P_{0}-P^{*}\right)}{2}\left\{1 \mp \frac{\alpha+\beta-1}{\sqrt{(1+\alpha-\beta)^{2}-4 \alpha}}\right\}$.

Case 2. $(1+\alpha-\beta)^{2}=4 \alpha$ (Repeated Real Roots):

$P_{t}=\left(A_{3}+A_{4} t\right)\left\{\frac{1+\alpha-\beta}{2}\right\}+P^{*}$,

where

$A_{3}=\frac{2\left(P_{0}-P^{*}\right)}{1+\alpha-\beta}$

and

$A_{4}=\frac{2 \beta\left(P^{*}-P_{0}\right)}{1+\alpha-\beta}$.

Case 3. $(1+\alpha-\beta)^{2}<4 \alpha$ (Complex Roots):

$P_{t}=\sqrt{\alpha}^{t}\left\{A_{5} \cos (\theta t)+A_{6} \sin (\theta t)\right\}+P^{*}$,

where

$$
A_{5}=P_{0}-P^{*} \quad A_{6}=\frac{(\alpha+\beta-1)\left(P_{0}-P^{*}\right)}{\sqrt{4 \alpha-(1+\alpha-\beta)^{2}}}
$$

and

$\theta=\arccos \frac{1+\alpha-\beta}{2 \sqrt{\alpha}}$,

Amplitude $=\sqrt{A_{5}^{2}+A_{6}^{2}} \sqrt{\alpha}^{t}$,

Frequency $=\frac{\theta}{2 \pi}$. 
Figure A1 - Stability of equilibrium. The area inside the triangle is the stable region for the difference equation. $\alpha$ is the serial correlation parameter and $\beta$ is the mean reversion parameter.

\section{The Stable Region}

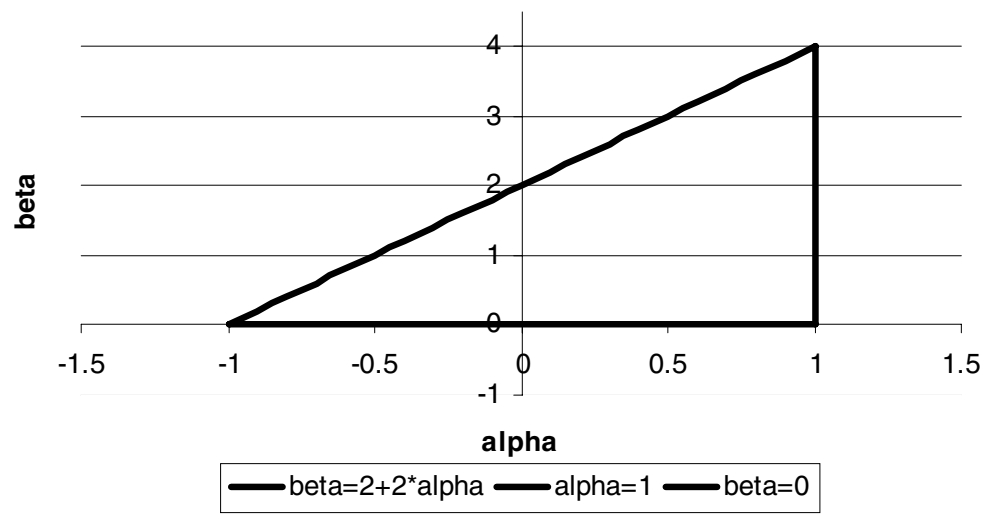

\section{Stability of Equilibrium}

The necessary and sufficient condition for the solution to be stable is that the moduli of the roots of the characteristic equation be both less than one. The modulus of a complex number is the square root of the sum of the square of the real and imaginary parts. The modulus of a real number is the absolute value of the number (Sysdaeter and Hammond 1995, p. 756).

There are two cases:

- If the characteristic equation has complex roots, then the modulus of each root is $\sqrt{\alpha}$. Therefore for stability, $\alpha<1$ is required.

- If the characteristic equation has real roots, then the absolute value of each root must be less than one. This requirement reduces to the two conditions $\beta>0$ and $\beta<2+2 \alpha$.

These three conditions are represented graphically by the area inside the triangle in Figure A1.

\section{Appendix B: Data Sources and Definitions}

Median sales price of existing homes: National Association of Realtors Real Estate Outlook; annual data, except that latest year is the arithmetic mean of quarterly prices. 
Metro area population: Annual mid-year estimate, Bureau of the Census; supplied by the Bureau of Economic Analysis.

Total employment, metro area: Bureau of Economic Analysis.

Nominal personal income per capita: Bureau of Economic Analysis.

Local area construction cost indexes: R.S. Means Handbook.

State average property tax rates (used in calculating homeowner's percent cost of capital): American Council on Intergovernmental Relations Significant Features of Fiscal Federalism, 1994. The property tax series is published only occasionally.

National average home mortgage interest rate (used in calculating homeowner's percent cost of capital): Economic Report of the President for the current year, or Statistical Abstract of the United States.

The annualized Consumer Price Index for all urban consumers (used in deflating income and house prices): Electronic edition of the Economic Bulletin Board, October 1995. The rate of change in the previous year is the expected inflation rate used in the user cost calculation.

\section{Appendix C: Metropolitan Areas Included in the Study.}

\section{Code Name and Census Name}

\section{Northern Atlantic Region}

Boston \& Boston-Worcester-Lawrence-Lowell-Brocktn, MA-NH

(NECMA)

Hartford \& Hartford, CT (NECMA)

Providence \& Providence-Warwick-Pawtucket, RI (NECMA)

New York \& New York-Northern New Jersey-Long Island, NY-NJ-CT-PA (CMSA)

\section{Middle Atlantic Region}

Baltimore \& Baltimore, MD (PMSA)

Philadelphia \& Philadelphia, PA-NJ (PMSA)

Washington DC \& Washington, DC-MD-VA-WV (PMSA)

\section{Southeastern Region}

Birmingham \& Birmingham (MSA)

Fort Lauderdale \& Fort Lauderdale, FL (PMSA)

Knoxville \& Knoxville, TN (MSA)

Louisville \& Louisville, KY-IN MSA

Memphis \& Memphis, TN-AR-MS MSA

Nashville \& Nashville, TN (MSA)

New Orleans \& New Orleans, LA (MSA)

Tampa \& Tampa-St. Petersburg-Clearwater, FL (MSA)

West Palm Beach \& West Palm Beach-Boca Raton, FL (MSA) 
Great Lakes Region

Akron \& Akron, OH (PMSA)

Albany \& Albany-Schenectady-Troy, NY (MSA)

Chicago \& Chicago-Gary-Kenosha, IL-IN-WI (CMSA)

Columbus \& Columbus, OH (MSA)

Detroit \& Detroit-Ann Arbor-Flint, MI (CMSA)

Grand Rapids \& Grand Rapids-Muskegon-Holland, MI (MSA)

Indianapolis \& Indianapolis, IN (MSA)

Milwaukee \& Milwaukee-Waukesha, WI (PMSA)

Minneapolis-St. Paul \& Minneapolis-St. Paul, MN-WI (MSA)

Rochester \& Rochester, NY (MSA)

Saint Louis \& Saint Louis, MO-IL (MSA)

Syracuse \& Syracuse, NY (MSA)

Great Plains Region

Des Moines \& Des Moines, IA (MSA)

Kansas City \& Kansas City, MO-KS (MSA)

Omaha \& Omaha, NE-IA (MSA)

Southwestern Region

Albuquerque \& Albuquerque, NM (MSA)

El Paso \& El Paso, TX (MSA)

Houston \& Houston-Galveston-Brazoria, TX (CMSA)

Oklahoma City \& Oklahoma City, OK (MSA)

Salt Lake \& Salt Lake City-Ogden, UT (MSA)

San Antonio \& San Antonio, TX (MSA)

Tulsa \& Tulsa, OK (MSA)

Dallas \& Dallas-Fort Worth, TX (CMSA)

\section{Southern California Region}

Los Angeles \& Los Angeles-Long Beach, CA (PMSA)

Orange County \& Anaheim-Santa Ana-Garden Grove (Orange County, CA)

Riverside-San Bernardino \& Riverside-San Bernardino, CA (PMSA)

San Diego \& San Diego, CA (MSA)

Northern Pacific Region

San Francisco \& San Francisco-Oakland, CA (CMSA) 